\title{
Influence of Virtual Experience Immersion, Product Control, and Stimulation on Advertising Effects
}

Hui Fei Lin, National Taiwan Normal University, Taiwan*

\begin{abstract}
With advances in communication technologies, virtual reality (VR) has become increasingly popular. This study investigated the influence of virtual experiences on advertising effects. A 2 (virtual experience immersion: high vs. low) $\times 2$ (virtual experience product control: high vs. low) $\times 2$ (virtual experience product stimulation: high vs. low) between-subjects design was conducted. The results revealed that compared with the low-immersion virtual experience, the high-immersion virtual experience produced better advertisement attitudes. Furthermore, virtual experiences with high product control generated better advertisement attitudes when compared with virtual experiences with low product control. The two-way interactions between virtual experience product stimulation and immersion and between virtual experience product stimulation and virtual experience product control induced better brand attitude and purchase intention. In addition, telepresence and perceived enjoyment mediated the relationship between virtual experience and advertisement attitudes.
\end{abstract}

\section{KEYWORDS}

Advertisement Attitude, Excitation-Transfer Theory, Immersion, Perceived Enjoyment, Telepresence, UserControlled Interactivity, Virtual Experience Product Stimulation, Virtual Reality

\section{INTRODUCTION}

As communication technologies have developed, virtual reality (VR) has become increasingly popular. VR is an environment created by computers or other media that gives the illusion of being in a real environment; VR can also be referred to as a virtual experience (Biocca, 1992). A virtual experience is considered as the psychological and emotional state that arises during interaction with a threedimensional (3D) virtual environment (Li et al., 2001). Based on previous research (e.g. Daugherty \& Biocca, 2005; Daugherty et al., 2008; Fiore et al., 2005), virtual experiences involve the concepts of immersion, user-controlled interactivity, and simulation. Regarding immersion, it refers to the extent to which the illusion of reality can be delivered to the senses of a human participant through media (Slater \& Wilbur, 1997). Waterworth and Waterworth (2001) indicated that the degree of immersion is determined by the technology used to develop the VR environment; the sense of immersion provided by a VR head-mounted display (HMD) is superior to that provided by a desktop VR experience. Users can experience 3D virtual environments simulated by computer systems by using an HMD. In an HMD, a location tracker transmits the user's location and perspective information to the computer, which then modifies the output of the virtual image accordingly. In addition, the objects in a virtual 
scene can be controlled using gloves. In a desktop VR experience, the virtual environment is created by software installed on a personal computer and displayed on a computer screen. This enables users to experience VR through devices such as a keyboard (McLellan, 1996). Applying VR to advertising can absorb consumers in brand communication, and to a certain extent, VR can provide a user with personal control over their advertising experience (Martin, 2017).

With respect to user-controlled interactivity in virtual environment, user-controlled interactivity refers to the interaction or input from a user that determines the user's experience (Spielmann \& Mantonakis, 2018). In a virtual experience, the sense of being in control of a product enables consumers to gain a compelling impression of both the advertisement and the product (Tian et al., 2014). In addition to a sense of immersion and control, stimulation is crucial in virtual experiences. Daugherty and Biocca (2005) suggested that consumers have meaningful experiences in product examination during virtual experiences that are similar to direct experiences. This is because the interactivity and user control provided by visual simulation yield stimulation. According to the excitation-transfer theory proposed by Zillmann (1996), emotional behaviors and experiences can be enhanced through a combination of the residual arousal or excitation experienced during previous stimulations and the excitatory response to existing simulations. Therefore, the arousal generated by a single emotioninducing stimulus can be transferred to another stimulus, causing the emotional arousal stimulated by the second stimulus to be stronger than the preexisting emotional arousal. This concept can be accurately illustrated by the feelings experienced on a roller coaster. The strong stimulation generated by the roller coaster's speed and sharp turns, despite causing nervousness and anxiety, can also foster perceived enjoyment and then induce better attitude toward this experiment.

Telepresence is also a dimension of VR, which can be defined as a stimulated or real environment in which users can participate in experiences that mediate their perception of an environment (Steuer, 1992). Telepresence is considered to entail a sense of presence or a nonmediated perceptual illusion (Lombard \& Ditton, 1997). Telepresence is the sense of immersion experienced in a mediated environment rather than a physical environment (Biocca, 1997). Therefore, telepresence can be considered the direct experience of a simulated perception (Coyle \& Thorson, 2001). Telepresence is a crucial concept in VR because it enables users to generate meaningful memories through a virtual experience in a virtual environment, which can induce behavioral responses in a real environment. Furthermore, the attitudes and behaviors generated in VR can also affect real-world (Bailey \& Witmer, 1994).

Although VR technology has been widely discussed, research on VR advertising remains limited. Therefore, this study explored the applications and effects of VR-based advertising. The purpose of this study is to examine whether virtual experience immersion, product control, and stimulation affect brand attitude, advertisement attitude and purchase intention. An experiment with a 2 (virtual experience immersion: high vs. low $) \times 2$ (virtual experience product control: high vs. low) $\times 2$ (virtual experience product stimulation: high vs. low) between-subjects design was conducted. In addition, this study explored the mediation effects of perceived enjoyment and telepresence.

\section{LITERATURE REVIEW}

\section{Virtual Reality}

VR comprises several technologies that create highly interactive and synthetic spatial environments characterized by advanced human-machine interaction (Mikropoulos \& Natsis, 2011). Alternatively, VR can be described as a computer-simulated environment in which users can interact with one another in a virtual space by using agents such as avatars (Sherman \& Craig, 2003). VR is thus a computersimulated 3D virtual environment in which users experience a sense of presence by wearing an HMD and fiber-optic data gloves (Greenbaum, 1992). Sherman and Craig (2003) defined VR as having four key elements: sensory feedback, interactivity, a virtual world and virtual space, and immersion. First, 
sensory feedback is a critical element of VR. Specifically, VR provides direct sensory feedbackmostly visual effects - to users by tracking the movements of their head, hands, and joints. Second, interactivity is the extent to which participants can immediately modify the content of the virtual environment. Third, virtual world and virtual space refer to the concept of a virtual world comprising a certain form of media - content that either exists only in the mind of the creator or which is also shared with others. When a user perceives objects in a virtual world and interacts with them through a VR system, they physiologically undergo immersion - the fourth key element of VR. Furthermore, VR generates an interactive display. That is, the degree of immersion is directly related to the number of sensory modalities that the medium can provide. Therefore, the sense of immersion plays a crucial role in the development of a successful virtual experience.

\section{Virtual Experiences}

Virtual experiences are facilitated by image interactivity technology such as VR (Merle et al., 2012). Image interactivity technology produces an indirect product experience, or a virtual experience (Keller, 1993). Hoch and Ha (1986) suggested that consumers have three types of product experiences: direct, indirect, and virtual. Direct experience involves actively watching, listening, touching, smelling, or tasting products. Indirect experience, by contrast, involves passively receiving limited sensory input of product attributes. Specifically, advertising is the most common form of indirect experience. Virtual experience is the conveyance of a specific experiential attribute that enables individuals to experience that attribute virtually in a mediated environment (Besharat et al., 2013). Virtual experiences enable consumers to evaluate product effectiveness before purchasing (Klein, 1998). In addition, 3D visualization enables users to examine a product from different angles. The level of control is directly related to how the product is presented and experienced through simulation (Daugherty et al., 2008).

The concept of virtual experience emerged with the transition toward multisensory interactions that merge high-quality visuals, stereophony, and vibrant images made possible by developments in science and technology (Fiore et al., 2005). Research on virtual experiences, particularly the study by Krijin et al. (2004), has indicated that VR experiences are sufficiently immersive to stimulate users' senses and emotions. Moreover, Klein (1998) suggested that interactive 3D media can be used to simulate shopping environments, in which consumers can feel a sense of presence and "touch" products, thereby immersing them in the virtual environment through human-computer interaction. Li et al. (2001) argued that virtual experiences are simulations of real and physical experiences that occur in a computer-mediated environment and fall between direct and indirect experiences on a spectrum based on a user's product knowledge. According to relevant research, virtual experiences are characterized by the following three critical concepts: immersion, interaction, and stimulation.

\section{Immersion}

VR is not only a manifestation of psychological immersion; rather, it is more of a presentation of physical immersion (Sherman \& Craig, 2003). In psychological immersion, a user feels involved and is absorbed (Quarrick, 1989), whereas in physiological immersion, users are immersed through their physical senses. In the context of VR, immersion refers to physiological immersion, which replaces or expands a user's sensory stimulation (Sherman \& Craig, 2003). Therefore, physiological immersion is essential for VR. McGloin et al. (2013) defined immersion as a sense of virtual involvementimmersion is the extent to which a medium delivers a vivid illusion of reality through multisensory input (Slater \& Wilbur, 1997). Websites have low presence because of their limited interactive space and their lack of multisensory input. Therefore, websites are considered low-immersion virtual environments. Because VR is capable of creating a perceptual vividness that reinforces the feeling of having a real experience, it is considered a highly immersive virtual environment (Ahn $\&$ Bailenson, 2011). Thus, VR differs from conventional computer-based graphical displays in that it gives participants a sense of immersion in a mediated environment (Moore et al., 2002). In short, VR provides individuals with brand-new perspectives. 
User immersion in mediated environments can be influenced by the balance of accessibility between nonmediated and mediated information (Gerrig, 1993). Biocca (1995) suggested that stimuli from physical and virtual environments compete for a user's attention and that the ratio of the two types of stimuli input to the sensory channel is a factor determining a user's sense of presence. When the information originating from a nonmediated physical environment is reduced, a user may more easily experience telepresence (Kim \& Biocca, 1997).

Waterworth and Waterworth (2001) suggested that sensory fidelity produced by immersion allocates attention in a manner that suspends subjective disbelief, thereby producing high presence and greater task performance. Li et al. (2002) manipulated sensory immersion by modifying screen size and product dimensions (two-dimensional [2D] vs. 3D). Their results revealed that sensory immersion positively influences brand attitudes, product knowledge, and purchase intention. Based on the literature review, Hypothesis 1 was proposed:

H1: Compared with low-immersion virtual experiences, high-immersion virtual experiences will generate better brand attitude (1a), advertisement attitude (1b), and purchase intention (1c).

\section{User-Controlled Interactivity}

Rafaeli (1988) described interactivity as the responsiveness of users. Newhagen and Rafaeli (1996) suggested that a communication process is interactive if responses are exchanged instantly. $\mathrm{Li}$ et al. (2002) defined interactivity as the ability to select the timing, content, and sequence of a communication act in a mediated environment that users are able to control. Steuer (1992) suggested that interactivity involves three factors: speed, which is the time required to input a message into a mediated environment; range, which is the number of actions that can occur at a given time; and mapping, which is the controlled capacity to react to changes in a virtual world. Similarly, Lombard and Snyder-Duch (2001) indicated that interactivity comprises five critical components: acceptable input, modifiable quantity and type, range of response, response speed, and degree of consistency between input and output. Ariely (2000) argued that the concept of interactivity can be replaced with the concept of user control. On the basis of the aforementioned literature review, this study focused on user-controlled interactivity.

In the context of user-controlled interactivity, VR can reflect user actions (Sherman \& Craig, 2003). According to Sherman and Craig (2003), VR users can modify places, select objects, and place items, among numerous other actions, in a virtual world. In particular, VR enables users to move their bodies in the virtual world and modify their perspective depending on the angle of their head. For example, in flight simulation, users may need to simulate the details of various flights, including the airflow conditions and cockpit layout, by using a computer. By employing user-controlled interactivity, users can produce computer simulations that accurately represent night flights, takeoffs, and landings. In the context of advertising, interaction is crucial because it enables users to participate in the persuasion process (Ahn \& Bailenson, 2011). For example, Coyle and Thorson (2001) found that when website interactivity levels increase, the degree of perceived telepresence also increases. Furthermore, they indicated that websites with higher levels of interactivity produce more positive attitudes. Coyle and Thorson (2001) also suggested that websites with high levels of interactivity are similar to direct product experiences because they have a similar interactivity-based impact on brand attitudes and subsequent behavioral intentions. From this perspective, Hypothesis 2 was proposed:

H2: Compared with virtual experiences with low product control, virtual experiences with high product control will generate better brand attitude ( $2 a)$, advertisement attitude ( $2 b)$, and purchase intention (2c). 


\section{Stimulation}

VR provides users with a sense of immersion and interaction as well as a sense of stimulation. Wodehouse and Abba (2016) discovered that people who are more likely to be immersed in external stimuli enjoy virtual shopping experiences more. According to the appraisal theory of emotion, the favorable evaluations produced by external stimuli trigger positive emotion, and vice versa (Parkinson \& Manstead, 1992). Affective valence refers to the pleasantness of receiving stimuli, and positive and negative valence refer to attractive and aversive stimuli, respectively (Kensinger, 2004). Notably, emotional stimuli are easier to remember and are more vivid. Emotional stimuli cause a phenomenon called memory emotional enhancement, which is the enhancement of attention to emotional items as they are being encoded (Talmi et al., 2008). Therefore, a high affective valence tends to enhance attention. As in the example of the roller coaster, experiencing simulated high speed, high elevation, and weightlessness will arouse enjoyment in a passenger; consequently, the passenger experiences a pleasant feeling, even during such a stimulating and scary process. Moreover, in terms of experiential marketing, the pleasantness generated by a surprising and exciting product experience can induce an affinity for the product.

Furthermore, excitation-transfer theory suggests that if a secondary arousing stimulus is presented before the initial stimulus finishes, the residual arousal shifts to the secondary stimulus (Bryant \& Miron, 2003). Specifically, when a stimulus causes physiological arousal, the arousal ebbs over time. However, if an additional stimulus is presented before the initial arousal has ebbed, the individual's attention shifts to the new stimulus, and the residual arousal is incorporated into the new physiological arousal because of the individual's misattribution (Bryant \& Miron, 2003). When an individual is subject to stimulation, the sympathetic nervous system is activated, causing a nonspecific physiological arousal (Zillmann, 1983), which begins declining immediately as the parasympathetic nervous system releases hormones to counteract the response. The residual arousal is incorporated into the arousal stimulated by the existing stimulus. Excitation-transfer theory thus suggests that the arousal effect of the first incident gradually fades and that the residual arousal transfer is triggered by subsequent arousals (Zillmann, 1996). However, when the final positive incident occurs, the feeling of happiness intensifies, maximizing the user's sense of hedonism (Bryant \& Miron, 2003). The combination of these two arousals can cause a heightened emotional response toward the second incident (Zillmann, 1971). If stimulation is provided through a virtual experience with high immersion and control, such as a roller coaster ride, then the stimulation will be positive unless the excitement is sufficiently strong to instill a sense of fear (Heath et al., 2015). This study extended Zillmann's excitation-transfer theory to VR by determining whether stimulation generated by virtual product experience can be used to induce positive brand attitude, thereby increasing purchase intention. According to these rationales, Hypothesis 3 was developed:

H3: Compared with virtual experiences with low product stimulation, virtual experiences with high product stimulation will generate better brand attitude (3a), advertisement attitude (3b), and purchase intention $(3 \mathrm{c})$.

\section{Mediation Effect: Telepresence and Perceived Enjoyment}

Telepresence, a crucial concept in VR, refers to the sense of presence felt in a mediated virtual world (Steuer, 1992). Kim \& Biocca (1997) further divided telepresence into two dimensions: "arrival," which is the feeling of being in a mediated virtual environment, and "departure," which is the feeling of not being in a physical environment. Although individuals may be far away from a real place, they can still gain a sense of presence through computer-generated 3D virtual images, which can promote a sense of reality (Qiao et al., 2008). Similarly, Ahn and Bailenson (2011) and Van Damme et al. (2019) found that high immersion results in a high sense of presence. In addition, if users have low interactivity control, their level of experienced telepresence is attenuated (Klein, 2003). Moreover, 
Cauberghe et al. (2011) found that telepresence mediates the relationship between the perceived interactivity of television programs and advertisement attitudes. Furthermore, if users perceive a strong sense of control in a VR environment, they will focus on their interaction with the VR space. Consequently, users will experience a perceptual illusion of nonmediation, which increases their sense of presence (Gorini et al., 2011). Coyle and Thorson (2001) suggested that increases in interactivity levels are associated with increases in the feeling of telepresence. Similarly, Ahn et al. (2016) found that by increasing the control of stimuli in a virtual space, users' perception of telepresence in a mediated environment can be enhanced. Regarding stimulation, Klein (2003) indicated that because of a lack of sensory stimulation, users were unable to achieve sufficient telepresence in products. Chessa et al. (2016) suggested that telepresence could be achieved through the virtual stimuli provided by VR devices. Suh and Chang (2006) mentioned that online stores use VR interfaces for presenting products, which creates a higher level of telepresence for users when compared with the use of only photos and videos.

Addressing perceived enjoyment in terms of immersion, Yim et al. (2012) found that compared with traditional 2D television advertisements, stereoscopic 3D advertisements elicit higher levels of enjoyment. This occurs because the presence-inducing characteristics of immersive devices can enhance enjoyment (Tamborini \& Bowman, 2010). Similarly, Van Damme et al. (2019) indicated that higher levels of immersion result in higher levels of enjoyment. Regarding interactivity control, Nicholas et al. (2000) found that video games with higher levels of interactivity induce higher perceptions of enjoyment. Makransky et al. (2020) also indicated that compared with videos, interactive and immersive VR experiences increase levels of enjoyment. Concerning stimulation, the excitation-transfer theory suggests that the negative effects caused by suspense in horror movies can be transformed into enjoyment as the effect of the threat in the movie subsides. Thus, through transferred arousal, the negative experience induced by such a film can enhance the audience's enjoyment because they will feel relieved after witnessing the film's resolution (Zillmann, 1980). Hoffner and Cantor (1991) has found a correlation between this type of negative effect and enjoyment of horror movies; however, the resolution of the threat does not diminish the correlation. Despite causing nervousness and anxiety, a roller coaster can foster enjoyment because of the strong sense of stimulation it induces. According to relevant research (Daugherty \& Biocca, 2005; Daugherty et al., 2008; Fiore et al., 2005), virtual experiences involve immersion, control, and simulation. Therefore, when mediation analysis is conducted, a high level of virtual experience implies high levels of immersion, control, and stimulation. Hence, a low level of virtual experience implies low levels of immersion, control, and stimulation. Based on the literature review, Hypotheses 4 and 5 were proposed:

H4: Telepresence mediates the relationship between virtual experience and advertisement attitude.

H5: Perceived enjoyment mediates the relationship between virtual experience and advertisement attitude.

\section{METHODS}

A 2 (virtual experience immersion: high vs. low) $\times 2$ (virtual experience product control: high vs. low) $\times 2$ (virtual experience product stimulation: high vs. low) between-subjects experiment was conducted. The participants were recruited from a university to virtually experience a new bicycle and were given a printed advertisement of the bicycle, which included its brand name (SBIKE) and "super speed" slogan (Figure 1). The brand name and slogan were fictional. After reading the advertisement, the participants engaged in one of the eight VR experiences. Both the practice and real experiments were limited to approximately $15 \mathrm{~min}$. After the experience, the participants were asked to complete a questionnaire.

Manipulations 


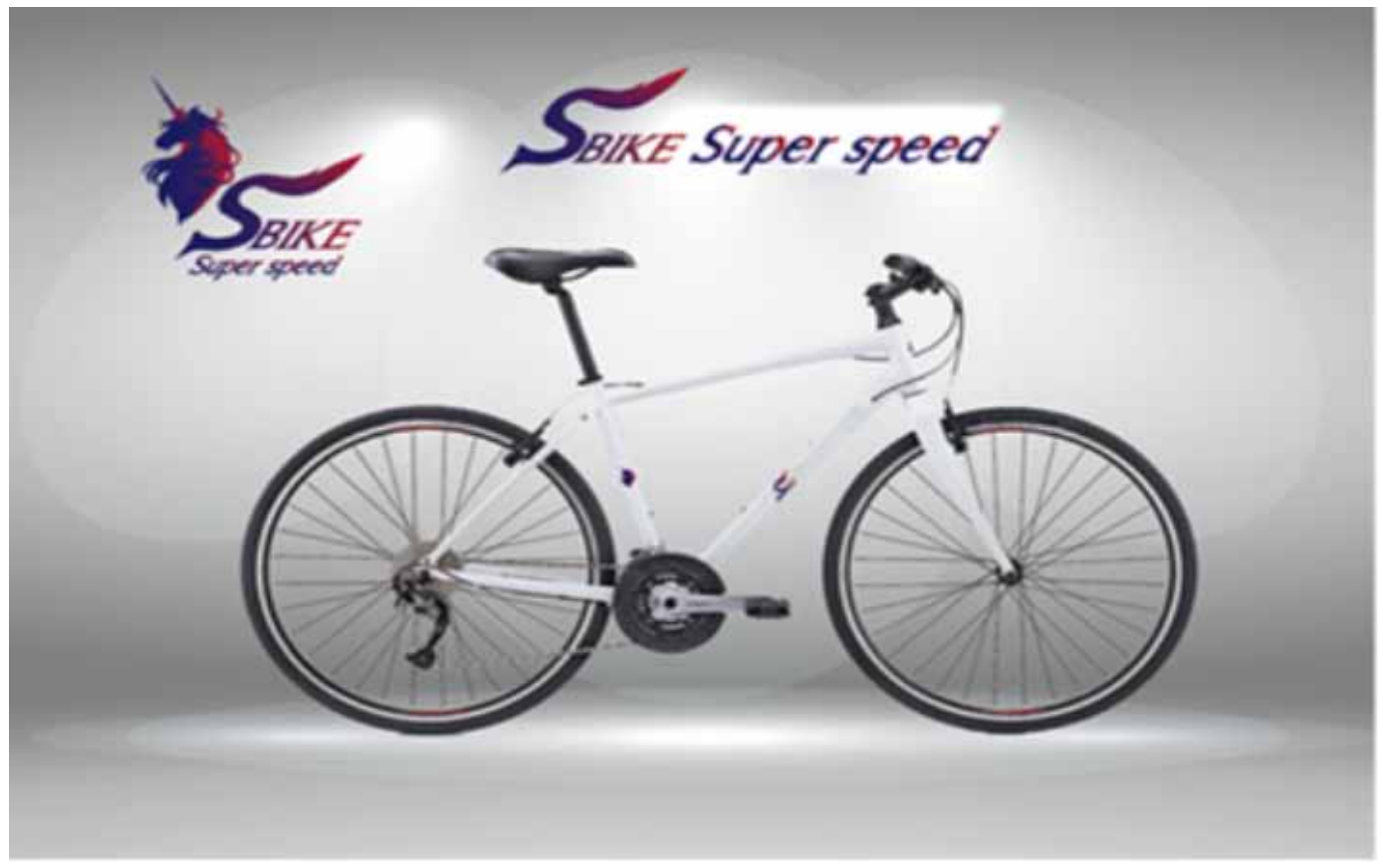

\section{Virtual Experience Immersion}

The high-immersion condition involved immersive VR, in which the user could experience 3D virtual environments through the HMD. A location tracker transmitted the user's location information to the computer, which modified the output virtual image. The experiment employed the HTC VIVE HMD VR device, which enables users to immerse themselves in a $360^{\circ}$ space. The low-immersion condition was a virtual experience produced using a desktop computer, through which users could view 3D virtual environments on a computer screen.

\section{Virtual Experience Product Control}

In the high control condition, participants could control the direction and speed of the bicycle by using handlebars and pedals. In the low control condition, participants could only sit on the bicycle and experienced the sense of cycling forward by viewing the changing scenery on a computer screen.

\section{Virtual Experience Product Stimulation}

In the high stimulation condition, participants rode a bicycle on a single-plank bridge over a river (Figure 2). In the low stimulation condition, participants rode a bicycle through a flat, scenic area (Figure 3). After the two versions were designed, 20 people were recruited for the pretest. The pretest included items such as "When virtually experiencing bicycle riding, I felt nervous, a quickened heartbeat, sweaty hands, and faster breathing." A 7-point Likert-type scale ranging from 1 (strongly disagree) to 7 (strongly agree) was employed to measure the participants' agreement with the items. The results of an independent-samples $t$ test indicated that the participants considered the virtual experience with high stimulation to have a more significant sense of stimulation than did the virtual experience with low stimulation $(M=4.13$ vs. $2.07, t=4.29, p<0.01)$.

The Measurement of The Mediator 
Journal of Global Information Management

Volume 30 • Issue 9

Figure 2. VR bicycle ride on a single-plank bridge

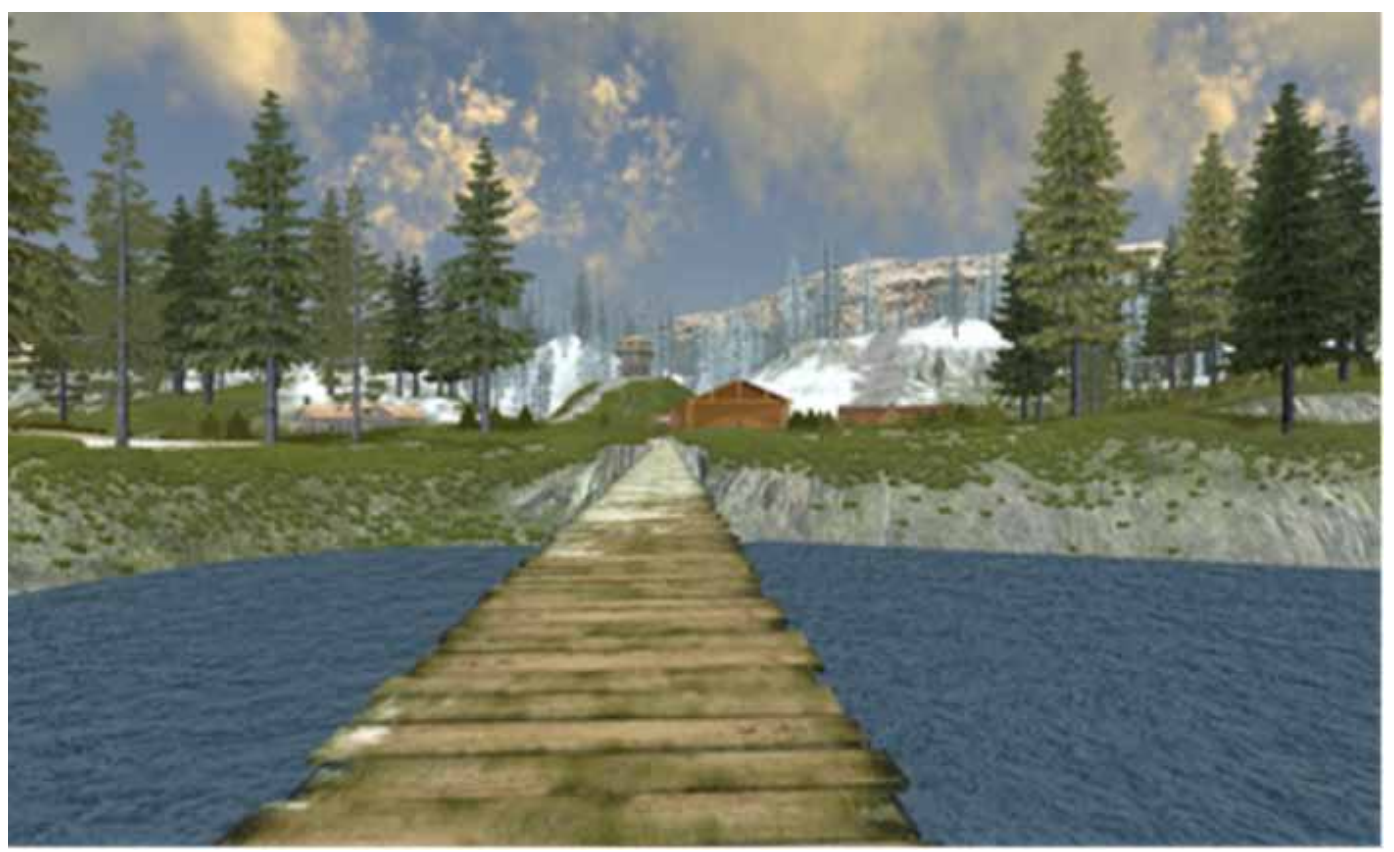

Figure 3. VR bicycle ride through a flat, scenic area

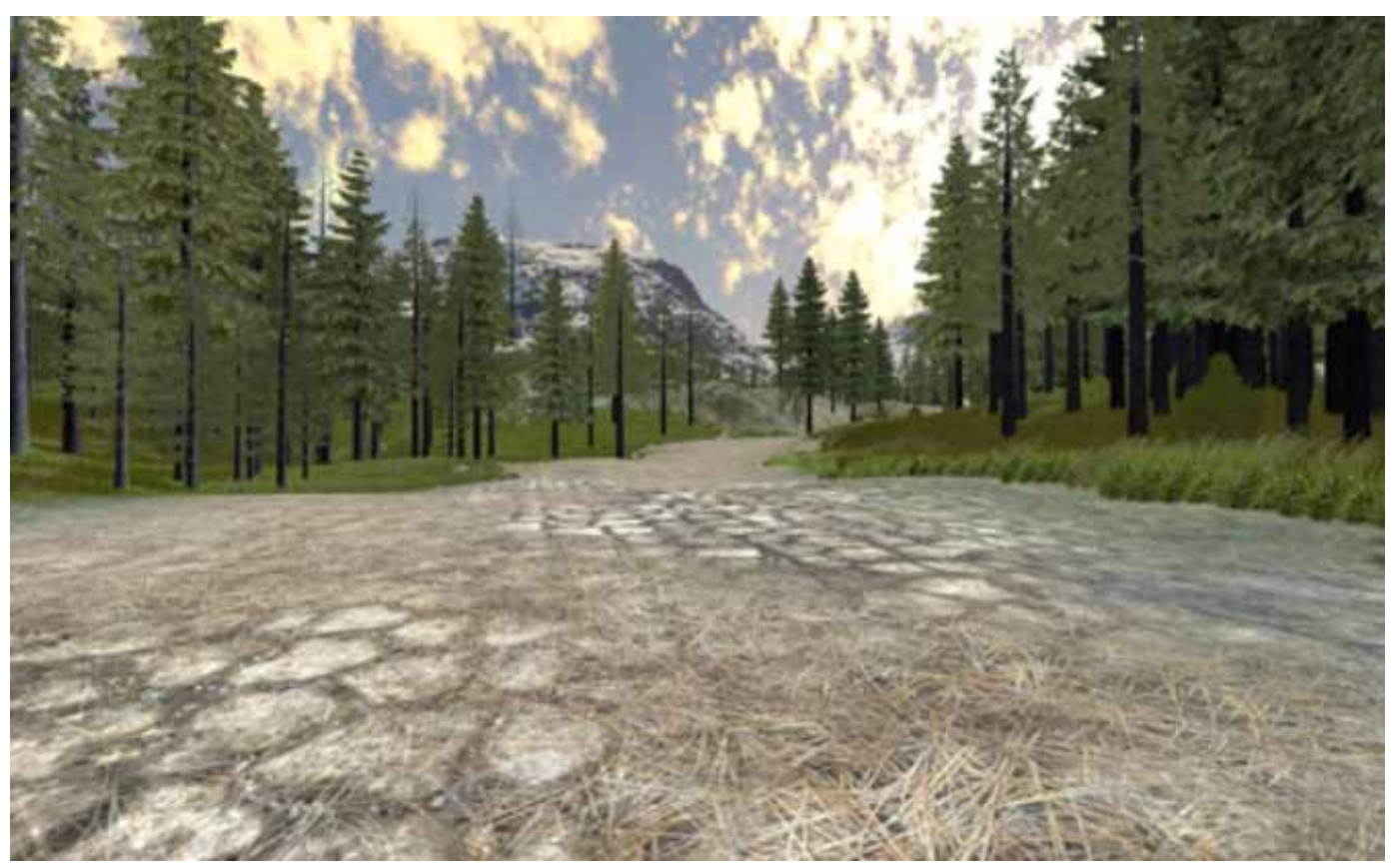




\section{Telepresence}

Telepresence was assessed using the following items developed by Klein (2003): "I like I was in the world the VR created"; "I forgot that I was in the middle of an experiment"; "My body was in the room, but my mind was inside the world created by the VR"; "The VR-generated world seemed to be somewhere I visited rather than something I saw"; "I felt I was more in the VR world than in the real world around me"; "I forgot about my immediate surroundings"; and "I felt like I came back to the real world after a journey” (p. 48; Cronbach's $\alpha=.89$ ).

\section{Perceived Enjoyment}

Perceived enjoyment was assessed using an adapted from McGloin and Embacher (2018). The item was "This virtual experience was entertaining, enjoyable, pleasing, and fun to use." A 7-point Likerttype scale ranging from 1 (strongly disagree) to 7 (strongly agree) was applied (Cronbach's $\alpha=.83$ ).

\section{Dependent Measures}

\section{Advertisement Attitude}

The scale developed by Muehling and Laczniak (1988) was revised and adapted to measure advertisement attitude according to the semantic differential items: "not attractive/attractive," "not good/good," "unpleasant/pleasant," "dull/dynamic," "depressing/refreshing," and "not convincing/ convincing" (Cronbach's $\alpha=.91)$.

\section{Brand Attitude}

Brand attitude was assessed on a six-item, 7-point scale ranging from 1 (bad, unappealing, unpleasant, unattractive, boring, unenjoyable) to 7 (good, appealing, pleasant, attractive, interesting, enjoyable) (Spassova \& Lee, 2013; Cronbach's $\alpha=.92$ ).

\section{Purchase Intention}

Purchase intention was assessed using a Likert-type scale ranging from 1 (strongly disagree) to 7 (strongly agree), which included items such as "I want to buy the products that appeared in the ad"; "I immediately considered buying the products that appeared in the ad"; and "In the future, I may consider purchasing the products that appeared in the ad" (Meyers-Levy \& Maheswaran, 2004; Cronbach's $\alpha=.93$ ).

\section{RESULTS}

The participants (77 males; 164 females) were recruited from a national university and were between the ages of 18 and 29. A t-test and multivariate analysis of variance (MANOVA) were used, respectively, to evaluate the manipulation checks and hypotheses.

\section{Manipulation Checks}

This study employed independent sample t-tests to determine whether the manipulations involved with immersion (high vs. low), control (high vs. low), and stimulation (high vs. low) were successful, and the 7-point Likert scale was used for measurement. The items concerning immersion, to be consistent with McGloin and Embacher (2018) were revised to "When virtually experiencing bicycle riding, I was engrossed in the situation"; "My sensory involvement was high"; and "I was highly engaged." The items about control were "During the virtual experience, I could control the direction of the bicycle"; "I could control the speed of the bicycle"; and I could move in the direction I wanted to see." For measuring stimulation, the items were "When virtually experiencing bicycle riding, I felt nervous, a quickened heartbeat, sweaty hands, and faster breathing." The results revealed that compared with the participants who used the desktop computer, the participants who used the HMD 
reported significantly higher levels of immersion $(M=6.01$ vs. $3.84, t=13.88, p<0.01)$. Compared with participants in the low control condition, the participants in the high control condition reported a significantly higher degree of control ( $M=4.67$ vs. $2.74, t=11.64, p<0.01)$. The participants in the high stimulation condition were significantly more stimulated ( $M=3.90$ vs. $2.44, t=8.52$, $p<0.01)$ than those in the low-stimulation condition. These results indicate that manipulation of immersion, control, and stimulation was successful.

\section{Hypothesis Testing}

A 2 (virtual experience immersion) $\times 2$ (virtual experience product control) $\times 2$ (virtual experience product stimulation) MANOVA was employed to examine brand attitude, advertisement attitude, and purchase intention. The results revealed that immersion $($ Wilks' $\Lambda=.96 ; F(3,229)=3.57 ; p<$ $\left.0.05 ; \eta^{2}=0.05\right)$ and control (Wilks' $\Lambda=.94 ; F(3,229)=4.66 ; p<0.01 ; \eta^{2}=0.06$ ) had significant main effects (Table 1). However, the main effect of stimulation had not significant (Wilks' $\Lambda=.98$; $\left.F(3,229)=1.98 ; p=0.12 ; \eta^{2}=0.03\right)$; therefore, H3 was not supported.

Table 1. Multivariate and univariate F-values for the dependent variables

\begin{tabular}{|l|l|l|l|l|}
\hline & MANOVA & Ad attitude & Brand attitude & Purchase intention \\
\hline Degrees of immersion (A) & $3.57^{*}$ & $10.31^{* *}$ & 1.13 & 1.05 \\
\hline Degrees of control (B) & $4.66^{* *}$ & $12.04^{* *}$ & .35 & .26 \\
\hline Degrees of stimulation (C) & 1.98 & 4.23 & .01 & .00 \\
\hline $\mathrm{A} \underline{\times} \mathrm{B}$ & 1.76 & .63 & 1.90 & 1.45 \\
\hline $\mathrm{A} \underline{\times} \mathrm{C}$ & $3.24^{*}$ & .34 & $6.41^{*}$ & $7.99^{* *}$ \\
\hline $\mathrm{B} \underline{\times} \mathrm{C}$ & $4.05^{* *}$ & .10 & .01 & $6.29^{*}$ \\
\hline $\mathrm{A} \times \mathrm{B} \times \mathrm{C}$ & 1.07 & .71 & .78 & .02 \\
\hline
\end{tabular}

Note: MANOVA df $=3 / 229$, univariate $\mathrm{df}=1 / 231$

${ }^{*} p<.05{ }^{* *} p<.01$

Regarding H1, compared with low immersion, high immersion generated better brand attitude (1a) and advertisement attitude (1b) and higher purchase intention (1c). Univariate analyses revealed that immersion had a significant main effect on advertisement attitude $(F(1,231)=10.31, p<0.01$, $\left.\eta^{2}=0.04\right)$. Specifically, when compared with low immersion, high immersion produced superior advertisement attitude ( $M=5.14$ vs. $4.39, t=3.21, p<0.01)$. However, immersion did not have a significant main effect on brand attitude $\left(F(1,231)=1.13, p=.29, \eta^{2}=0.01\right)$ or purchase intention $\left(F(1,231)=1.05, p=.31, \eta^{2}=0.01\right)$. Thus, the results supported H1a but not H1b or H1c.

Regarding H2, compared with low control, high control generated more positive brand attitude (2a) and advertisement attitude (2b) and higher purchase intention (2c). Univariate analyses indicated that control had a significant main effect on advertisement attitude $(F(1,231)=12.04, p<0.001$, $\left.\eta^{2}=0.05\right)$. Specifically, high control produced better advertisement attitude than did low control ( $M$ $=5.17$ vs. $4.36, t=3.47, \mathrm{p}<0.05)$. However, control did not have a significant main effect on brand attitude $\left(F(1,231)=.35, p=.56, \eta^{2}=0.00\right)$ or purchase intention $\left(F(1,231)=.26, p=.61, \eta^{2}=\right.$ $0.00)$. Thus, the results supported $\mathrm{H} 2 \mathrm{~b}$ but not $\mathrm{H} 2 \mathrm{a}$ or $\mathrm{H} 2 \mathrm{c}$.

There was no three-way interaction among immersion, control, and stimulation (Wilks' $\Lambda=$ $\left..97, F(3,229)=1.07, p=.36, \eta^{2}=.01\right)$. However, notably, the results revealed significant two-way interactions between "immersion" and "stimulation" (Wilks' $\Lambda=.96, F(3,229)=3.24, p<0.05, \eta^{2}$ $=.04$ ) and between "control" and "stimulation" (Wilks' $\Lambda=.95, F(3,229)=4.05, p<0.01, \eta^{2}=$ 
.05). Univariate analyses indicated significant interactions between "immersion" and "stimulation" for brand attitude $\left(\mathrm{F}(1,231)=6.41, p<0.05, \eta^{2}=0.02\right)$ and purchase intention $(F(1,231)=7.99, p<$ $\left.0.01, \eta^{2}=0.03\right)$. Post hoc multiple comparisons revealed that among low stimulation, high immersion produced better brand attitude than did low immersion $(M=5.01$ vs. $4.48, t=2.53, p<0.05)$. Among high immersion, lower stimulation produced better brand attitude than did high stimulation $(M=$ 4.00 vs. $3.52, t=2.01, p<0.05)$, whereas among low immersion, high stimulation produced better brand attitude than did low stimulation $(M=3.38 \mathrm{vs} .3 .33, t=1.98, p<0.05)$. In addition, univariate analyses indicated that significant interactions between "control" and "stimulation" for purchase intention $\left(F(1,231)=6.29, p<0.05, \eta^{2}=0.03\right)$. Specifically, among low stimulation, high control generated higher purchase intention than did low immersion $(M=3.93$ vs. $3.41, t=231, p<0.05)$.

\section{Mediation Analysis}

Mediation analysis was employed to determine whether telepresence and perceived enjoyment mediated the relationship between virtual experience (high immersion, control, and stimulation $=$ 1; low immersion, control, and stimulation $=0$ ) and advertisement attitude. This study applied the process model by Hayes (2013) to analyze the mediation effect, and samples were obtained through bootstrapping by performing 5,000 resamplings. Regarding the mediation effect of telepresence, the indirect effect was nonsignificant, and the $95 \%$ confidence interval did not include zero $(.60,1.73)$. The direct effect of virtual experience on advertisement attitude did not reach significance after perceived telepresence was included $(\beta=.44$, S.E. $=.37, p>0.05$; Figure 4$)$, indicating full mediation. Regarding the mediation effect of perceived enjoyment, the indirect effect was nonsignificant, and the $95 \%$ confidence interval did not include zero $(.47,1.64)$. The direct effect of virtual experience on advertisement attitude did not reach significance after perceived enjoyment was included $(\beta=.64$, S.E. $=.34, p>.05$; Figure 5), indicating full mediation. Therefore, the results supported $\mathrm{H} 4$ and $\mathrm{H} 5$.

Figure 4. Mediation effect of telepresence on virtual experience and advertisement attitude

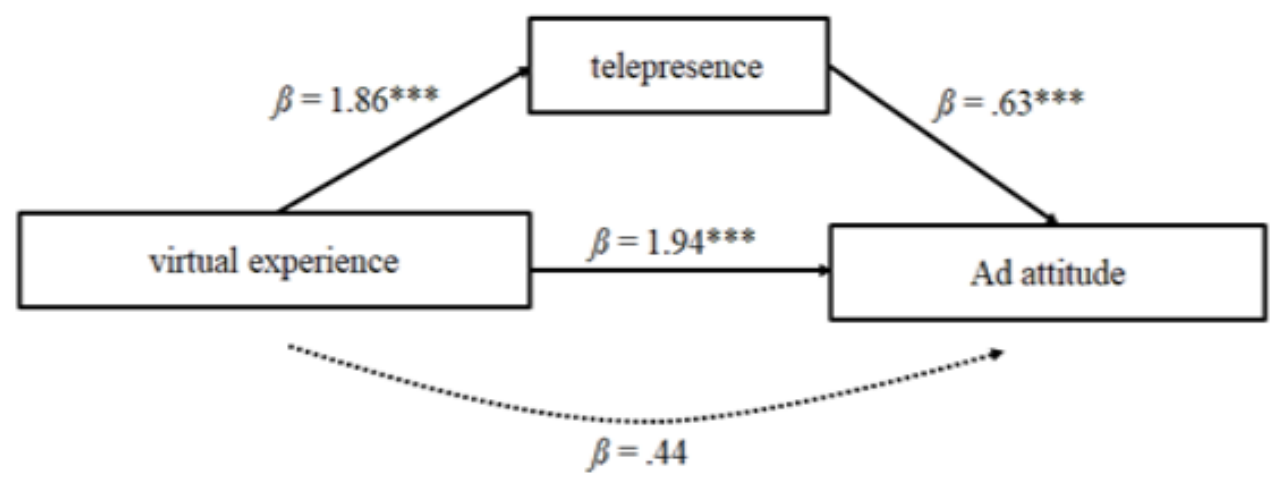

Note: Numbers above the solid lines are direct effects; the number below the dotted curved line is effect of virtual experience, controlling for perceived enjoyment.

$* * p<.001$ 


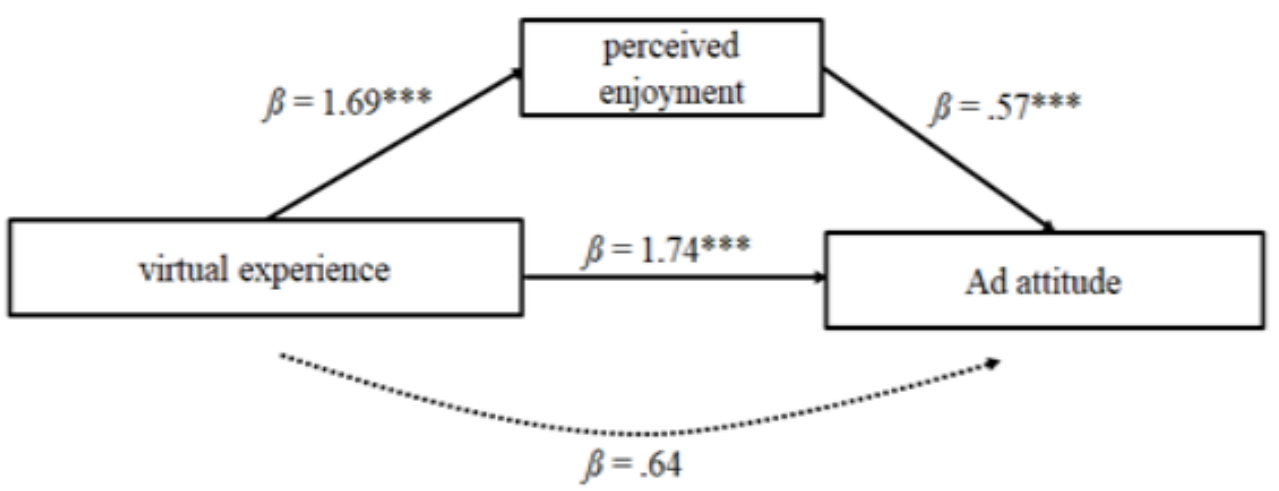

Note: Numbers above the solid lines are direct effects; the number below the dotted curved line is effect of virtual experience, controlling for perceived enjoyment.

${ }^{* * *} p<.001$

\section{DISCUSSION AND CONCLUSIONS}

This study explored the advertising effects of virtual experiences. The research findings are discussed in the following sections.

\section{Effects of Virtual Experience Immersion and Virtual Experience Stimulation on Advertisement Attitude}

The results of the current study supported H1, consistent with the findings of Van Kerrebroeck et al. (2017a), who found that VR experiences can increase consumer satisfaction. However, although the current study revealed that high-immersion virtual experiences generated better advertisement attitude than did low-immersion virtual experiences, high-immersion virtual experiences did not produce better brand attitude. Interestingly, immersion and stimulation exhibited a two-way interaction effect, which generated better brand attitude and higher purchase intention. In particular, during low-stimulation virtual experiences, high immersion produced better brand attitude than did low immersion. In high-immersion virtual experiences, low stimulation generated higher purchase intention than did high stimulation. In low-immersion virtual experiences, high stimulation leaded to higher purchase intention than did low stimulation. These findings are consistent with those of Carter and Allison (2017), who indicated that during roller coaster rides, people experience a sense of thrill from their intuitive perception of danger; however, because they know they are safe, people exhibit a positive attitude toward the thrill, thereby obtaining enjoyment from it. However, in VR, if such a thrill is overwhelming and exceeds an acceptable level of intensity, comfort is reduced, which can attenuate potential advertising effects. Because VR can produce a high sense of stimulation, if it is used for advertising, low-stimulation activities should be promoted to produce greater advertising effects. However, for virtual experiences facilitated by desktop computers, a greater sense of stimulation is required to enhance consumers' brand attitude and increase their purchase intention. The findings of the current study suggest that if the stimulation levels of virtual experiences are properly integrated, VR can be used to help consumers notice brands, improve their attitude toward brands, and even increase their purchase intention. 


\section{Effects of Virtual Experience Product Control and Virtual Experience Stimulation on Advertisement Attitude}

$\mathrm{H} 2$ was partially supported. The findings of the current study revealed that compared with virtual experiences with low product control, virtual experiences with high product control can improve advertisement attitude. Furthermore, an interaction effect was observed between product control and stimulation, increasing purchase intention. In particular, compared with virtual experiences with low product control where virtual experience stimulation was low, virtual experiences with high product control increased purchase intention. The interaction between control and stimulation was not significant effects on advertisement attitude or brand attitude because whether the product virtual experience was enabled through an HMD or a computer, advertisement attitude and brand attitude were both higher than the median value of 4 . The results of a one-sample t test exhibited significance $(M=5.15, t=5.80, p<0.01 ; M=4.82, t=7.68, p<0.001 ; M=4.39, t=2.91, p$ $<0.01 ; M=4.67, t=6.53, p<0.001)$. Overall, in the current study, immersion and control had significant effects on advertisement attitude. Especially, stimulation exhibited interaction effects on control and immersion, respectively. Therefore, when employing virtual experiences, advertisers should emphasize immersion and control and consider the complementary effects of stimulation to improve brand attitude and increase purchase intention.

\section{Mediation Effects of Telepresence and Perceived Enjoyment on the Relationship between Virtual Experience and Advertisement Attitude}

In the current study, telepresence mediated the relationship between virtual experience and advertisement attitude, which is consistent with the findings of relevant studies. Jang et al. (2019) found that consumers' perceptions of high interactivity, combined with high perceptions of telepresence, positively influenced their perceptions of virtual shopping experiences and their attitudes toward VR stores. Similarly, Van Kerrebroeck et al. (2017b) indicated that VR has higher telepresence than conventional 2D videos and can affect advertisement attitude through telepresence. Spielmann and Mantonakis (2018) found that virtual tours with heightened telepresence can improve advertisement attitudes. In addition, As McGloin et al. (2013) stated, presence enables users to have real-life experiences, and to produce responses similar to direct experiences. Thus, users can experience more physical arousal. Therefore, high-immersion virtual experiences should be combined with a high degree of control and stimulation to produce a high perception of telepresence, which will generate more positive advertisement attitude.

The current study revealed that perceived enjoyment mediated the relationship between virtual experience and advertisement attitude. The results can be explained by excitation-transfer theory, which demonstrates how physiological arousal is affected by stimulation and the manner by which emotions influence the reactions generated by a subsequent stimulus (Zillmann, 1996). During highly stimulating VR experiences such as riding a bicycle on a single-plank bridge, participants can experience the transfer from high stimulation to enjoyment, which is obtained after successfully crossing the bridge. Thus, the user will form a positive attitude. This finding is consistent with the results of Van Kerrebroeck et al. (2017a), who indicated that enjoyable VR experiences lead to positive consumer responses. The findings of the current study are also consistent with the findings of Ching et al. (2013), who found that advertising can make consumers aware of perceived enjoyment, thereby generating positive attitudes. These viewpoints illustrate that perceived enjoyment can mediate the relationship between virtual experience and advertisement attitude. Consequently, in the current study, telepresence and perceived enjoyment both exhibited mediating influences on virtual experience and advertising effects, and their crucial roles should not be ignored in the context of advertising.

Regarding theoretical and practical implications, the current study explored the influence of virtual experience immersion, control, and stimulation on advertising effects and examined whether telepresence and perceived enjoyment mediated the relationship between virtual experience and advertisement attitude. Although VR usage is gradually increasing, research on VR advertising 
remains limited. The current study can serve as a reference for future studies on VR advertising and its applications. The findings can provide marketing communication practices about ways to use VR advertising to reach consumers. Regarding research limitations and directions for future research, some participants reported discomfort due to dizziness while using the HMD, which may have affected the research results. Future studies could focus on smartphone VR advertising applications. In the VR industry, 2016 is identified as "the first year of VR," and mobile VR devices are predicted to soon become mainstream. Therefore, the effects of mobile VR advertising will soon become a critical research direction. Thus, future studies can extend the research by expanding the scope of VR advertising, which would facilitate the development of relevant new theories.

\section{ACKNOWLEDGEMENTS}

This study was supported by the Ministry of Science and Technology, Taiwan, R.O.C. under Grant no. MOST 108-2410-H-003 -124 -MY2 


\section{REFERENCES}

Ahn, S. J., \& Bailenson, J. N. (2011). Self-endorsing versus other-endorsing in virtual environments. Journal of Advertising, 40(2), 93-106. doi:10.2753/JOA0091-3367400207

Ahn, S. J., Bostick, J., Ogle, E., Nowak, K. L., McGillicuddy, K. T., \& Bailenson, J. N. (2016). Experiencing nature: Embodying animals in immersive virtual environments increases inclusion of nature in self and involvement with nature. Journal of Computer-Mediated Communication, 21(6), 399-419. doi:10.1111/jcc4.12173

Arens, W., \& Weigold, M. (2021). Contemporary Advertising and Integrated Marketing Communications (16th ed.). McGraw-Hill.

Ariely, D. (2000). Controlling the information flow: Effects on consumers' decision making and preferences. The Journal of Consumer Research, 27(2), 233-248. doi:10.1086/314322

Bailey, J. H., \& Witmer, B. G. (1994). Learning and transfer of spatial knowledge in a virtual environment. Proceedings of the Human Factors and Ergonomics Society Annual Meeting, 38(18), 1158-1162. doi: $10.1086 / 314322$

Bao, Y., Cheng, X., \& Zarifis, A. (2021). Exploring the impact of country-of-origin image and purchase intention in cross-border E-commerce. [JGIM]. Journal of Global Information Management, 30(2), 1-20. doi:10.4018/ JGIM.20220301.oa7

Besharat, A., Kumar, A., Lax, J. R., \& Rydzik, E. J. (2013). Leveraging virtual attribute experience in video games to mprove Brand Recall and Learning. Journal of Advertising, 42(2-3), 170-182. doi:10.1080/009133 67.2013.774593

Biocca, F. (1992). Virtual reality technology: A tutorial. Journal of Communication, 42(4), 23-72. doi:10.1111/j.1460-2466.1992.tb00811.x

Biocca, F. (1995). Intelligence augmentation: The vision inside virtual reality. In B. Gorayska \& J. Mey (Eds.), Cognitive Technology. North Holland.

Biocca, F. (1997). The cyborg's dilemma: Progressive embodiment in virtual environments. Journal of ComputerMediated Communication, 3(2), 1-18. doi:10.1111/j.1083-6101.1997.tb00070.x

Bryant, J., \& Miron, D. (2003). Excitation-transfer theory and three-factor theory of emotion. In J. Bryant, D. Roskos-Ewoldsen, \& J. Cantor (Eds.), Communication and emotion: Essays in honor of Dolf Zillmann (pp. 31-59). Erlbaum.

Carter, M., \& Allison, F. (2017). Fear, loss and meaningful play. Permadeath in DayZ. Journal of Gaming \& Virtual Worlds, 9(2), 143-158. doi:10.1386/jgvw.9.2.143_1

Cauberghe, V., Geuens, M., \& De Pelsmacker, P. (2011). Context effects of TV programme-induced interactivity and telepresence on advertising responses. International Journal of Advertising, 30(4), 641-663. doi:10.2501/ IJA-30-4-641-663

Chang, C. L.-h., \& Wu, S. (2021). Using Online Social Networks to Globalize and Popularize Product Brands in Different Cultural Areas. A Relational Network Model. [JGIM]. Journal of Global Information Management, 29(6), 1-30. doi: 10.4018/JGIM.20211101.oa38

Chessa, M., Maiello, G., Borsari, A., \& Bex, P. J. (2016). The perceptual quality of the oculus rift for immersive virtual reality. Human-Computer Interaction, 34, 51-82. doi:10.1080/07370024.2016.1243478

Ching, R. K., Tong, P., Chen, J.-S., \& Chen, H.-Y. (2013). Narrative online advertising: Identification and its effects on attitude toward a product. Internet Research, 23(4), 414-438. doi:10.1108/IntR-04-2012-0077

Cowan, K., Spielmann, N., Horn, E., \& Griffart, C. (2021). Perception is reality... How digital retail environments influence brand perceptions through presence. Journal of Business Research, 123, 86-96. doi:10.1016/j. jbusres.2020.09.058

Coyle, J. R., \& Thorson, E. R. (2001). The effects of progressive levels of interactivity and vividness in web marketing sites. Journal of Advertising, 30(3), 65-78. doi:10.1080/00913367.2001.10673646 
Daugherty, T., \& Biocca, F. (2005). Experiential ecommerce: A summary of research investigating the impact of virtual experience on consumer learning. Online Consumer Psychology: Understanding and Influencing Consumer Behavior in the Virtual World, 457, 489.

Daugherty, T., Li, H., \& Biocca, F. (2008). Consumer learning and the effects of virtual experience relative to indirect and direct product experience. Psychology and Marketing, 25(7), 568-586. doi:10.1002/mar.20225

De Regt, A., Plangger, K., \& Barnes, S. J. (2021). Virtual reality marketing and customer advocacy: Transforming experiences from story-telling to story-doing. Journal of Business Research, 136, 513-522. doi:10.1016/j. jbusres.2021.08.004

Devinney, T., Dowling, G., \& Collins, M. (2005). Client and agency mental models in evaluating advertising. International Journal of Advertising, 24(1), 35-50. doi:10.1080/02650487.2005.11072903

Erra, U., Malandrino, D., \& Pepe, L. (2019). Virtual reality interfaces for interacting with three-dimensional graphs. International Journal of Human-Computer Interaction, 35(1), 75-78.

Fiore, A. M., Jin, H., \& Kim, J. (2005). For fun and profit: Hedonic value from image interactivity and responses toward an online store. Psychology and Marketing, 22, 669-694. doi:10.1002/mar.20079

Gerrig, R. J. (1993). Experiencing Narrative Worlds. Yale University Press.

Gorini, A., Capideville, C. S., Leo, G. D., Mantovani, F., \& Riva, G. (2011). The role of immersion and narrative in mediated presence: The virtual hospital experience. Cyberpsychology, Behavior, and Social Networking, 14(3), 99-105. doi:10.1089/cyber.2010.0100

Greenbaum, P. (1992). The lawnmower man. Film and video, 9(3), 58-62.

Guilford J. P.(1964). Podstawowe metody statystyczne w psychologii i pedagogice. Warszawa, PWN, 157.[in Polish]

Hayes, A. F. (2013). Introduction to mediation, moderation, and conditional process analysis: A regressionbased approach. Guilford Press.

Heath, T. B., Chatterjee, S., Basuroy, S., Hennig-Thurau, T., \& Kocher, B. (2015). Innovation sequences over iterated offerings: A relative innovation, comfort, and stimulation framework of consumer responses. Journal of Marketing, 79(6), 71-93. doi:10.1509/jm.10.0413

Hoch, S., \& Ha, Y. W. (1986). Consumer learning: Advertising and the ambiguity of product experience. The Journal of Consumer Research, 13(2), 221-233. doi:10.1086/209062

Hoffner, C., \& Cantor, J. (1991). Factors affecting children's enjoyment of a frightening film sequence. Communication Monographs, 58(1), 41-62. doi:10.1080/03637759109376213

Jang, J. Y., Hur, H. J., \& Choo, H. J. (2019). How to evoke consumer approach intention toward VR stores? Sequential mediation through telepresence and experiential value. Fashion and Textiles, 6(1), 12. doi:10.1186/ s40691-018-0166-9

Jungbok, H. (2016). Multivariate analysis of variance in marketing research. Advances in Management, 9(9), 1-5.

Keller, K. L. (1993). Conceptualizing, measuring, and managing customer-based brand equity. Journal of Marketing, 57(1), 1-22. doi:10.1177/002224299305700101

Kensinger, E. A. (2004). Remembering emotional experiences: The contribution of valence and arousal. Reviews in the Neurosciences, 15(4), 241-252. doi:10.1515/REVNEURO.2004.15.4.241

Kim, T., \& Biocca, F. (1997). Telepresence via television: Two dimensions of telepresence may have different connections to memory and persuasion. Journal of Computer-Mediated Communication, 3(2). Advance online publication. doi:10.1111/j.1083-6101.1997.tb00073.x

Klein, L. R. (1998). Evaluating the potential of interactive media through a new lens: Search versus experience goods. Journal of Business Research, 41(3), 195-203. doi:10.1016/S0148-2963(97)00062-3

Klein, L. R. (2003). Creating virtual product experiences: The role of telepresence. Journal of Interactive Advertising, 17(1), 41-55. doi:10.1002/dir.10046 
Krijin, M., Emmelkamp, R. P., \& Olafsson, R. B. (2004). Virtual reality exposure therapy of anxiety disorder: A review. Clinical Psychology Review, 24, 259-281. doi:10.1016/j.cpr.2004.04.001

Li, H., Daugherty, T., \& Biocca, F. (2001). Characteristics of virtual experience in electronic commerce: A protocol analysis. Journal of Interactive Marketing, 15(3), 13-30. doi:10.1002/dir.1013

Li, H., Daugherty, T., \& Biocca, F. (2002). Impact of 3-D advertising on product knowledge, brand attitude, and purchase intention: The mediating role of presence. Journal of Advertising, 31(3), 43-57. doi:10.1080/00 913367.2002.10673675

Lombard, M., \& Ditton, T. (1997). At the heart of it all: The concept of presence. Journal of Computer-Mediated Communication, 3(2). Advance online publication. doi:10.1111/j.1083-6101.1997.tb00072.x

Lombard, M., \& Snyder-Duch, J. (2001). Interactive advertising and presence: A framework. Journal of Interactive Advertising, 1(2), 56-65. doi:10.1080/15252019.2001.10722051

Makransky, G., Andreasen, N. K., Baceviciute, S., \& Mayer, R. E. (2020). Immersive virtual reality increases liking but not learning with a science simulation and generative learning strategies promote learning in immersive virtual reality. Journal of Educational Psychology, 113(4), 719-735. doi:10.1037/edu0000473

Marek, O. (2021). Krzysztof, Rand, Ryszard, Z.(2021).Change in the level of agricultural development in the context of public institutions' activities-A case study of the NASC activities in Poland. Land (Basel), 10, 187.

Martin, E. J. (2017). How virtual and augmented reality ads improve consumer engagement. EContent (Wilton, Conn.), 40(3), 4-8.

McGloin, R., \& Embacher, K. (2018). Just like riding a bike: A model matching approach to predicting the enjoyment of a cycling exergame experience. Media Psychology, 21(3), 486-505. doi:10.1080/15213269.201 7.1311269

McGloin, R., Farrar, K., \& Krcmar, M. (2013). Video games, immersion, and cognitive aggression: Does the controller matter? Media Psychology, 16, 65-87. doi:10.1080/15213269.2012.752428

McLellan, H. (1996). Virtual Realities. Handbook of Research for Educational Communications and Technology, 457-487.

Meißner, M., Pfeiffer, J., Peukert, C., Dietrich, H., \& Pfeiffer, T. (2020). How virtual reality affects consumer choice. Journal of Business Research, 117, 219-231. doi:10.1016/j.jbusres.2020.06.004

Merle, A., Senecal, S., \& St-Onge, A. (2012). Whether and how virtual try-on influences consumer responses to an apparel web site. International Journal of Electronic Commerce, 16(3), 41-64. doi:10.2753/JEC10864415160302

Meyers-Levy, J., \& Maheswaran, D. (2004). Exploring message framing outcomes when systematic, heuristic, or both types of processing occur. Journal of Consumer Psychology, 14(1), 159-167. doi:10.1207/ s15327663jcp1401\&2_18

Mikropoulos, T. A., \& Natsis, A. (2011). Educational virtual environments: A ten-year review of empirical research (1999-2009). Computers \& Education, 56, 769-790. doi:10.1016/j.compedu.2010.10.020

Moore, K., Wiederhold, B. K., Wiederhold, M. D., \& Riva, G. (2002). Panic and agoraphobia in a virtual world. Cyberpsychology \& Behavior, 5(3), 197-202. doi:10.1089/109493102760147178

Muehling, D. D., \& Laczniak, R. N. (1988). Advertising's immediate and delayed influence on brand attitudes: Considerations across message-involvement levels. Journal of Advertising, 17(4), 23-34. doi:10.1080/009133 67.1988.10673126

Newhagen, J. E., \& Rafaeli, S. (1996). Why communication researchers should study the internet: A dialogue. Journal of Communication, 46(1), 4-13. doi:10.1111/j.1460-2466.1996.tb01458.x

Nicholas, S., Haldane, C., \& Wilson, J. R. (2000). Measurement of presence and its consequences in virtual environment. International Journal of Human-Computer Studies, 52(3), 471-491. doi:10.1006/ijhc.1999.0343

Parkinson, B., \& Manstead, A. S. R. (1992). Appraisal as a cause of emotion, in M.S. clark (Ed.). Review of personality and social psychology (Vol. 13), New York: Sage. 
Petty, R. E., \& Cacioppo, J. T. (1981). Issue involvement as a moderator of the effects on attitude of advertising content and context. Advances in Consumer Research. Association for Consumer Research (U. S.), 8, 20-24.

Qiao, Z. H., Li, Y. B., Kang, S. P., \& Zhu, Q. (2008). Design of UAV telepresence and simulation platform based on VR. In 2008 International Conference on Cyberworlds (pp. 520-524), IEEE.

Qin, H., \& Lei, J. (2019, September). The application of virtual reality technology in advertising communication. In 2019 International Conference on Virtual Reality and Intelligent Systems (ICVRIS) (pp. 73-76). IEEE.

Quarrick, G. (1989). Our sweetest hours: Recreation and the mental state of absorption. McFarland \& Co.

Rafaeli, S. (1988). From new media to communication. Sage annual review of communication research: Advancing communication science, 16, 110-134.

Sherman, W., \& Craig, A. (2003). Understanding Virtual Reality-Interface, Application And Design. Morgan Kaufmann Publisher, Inc., doi:10.1162/105474603322391668

Slater, M., \& Wilbur, S. (1997). A framework for immersive virtual environments (FIVE): Speculations on the role of presence in virtual environments. Presence (Cambridge, Mass.), 6(6), 603-616. doi:10.1162/pres.1997.6.6.603

Sohaib, O., Kang, K., \& Miliszewska, I. (2019). Uncertainty avoidance and consumer cognitive innovativeness in e-commerce. [JGIM]. Journal of Global Information Management, 27(2), 59-77. doi:10.4018/JGIM.2019040104

Spassova, G., \& Lee, A. Y. (2013). Looking into the future: A match between self-view and temporal distance. The Journal of Consumer Research, 40(1), 159-171. doi:10.1086/669145

Spielmann, N., \& Mantonakis, A. (2018). In virtuo: How user-driven interactivity in virtual tours leads to attitude change. Journal of Business Research, 88, 255-264. doi:10.1016/j.jbusres.2018.03.037

Steuer, J. (1992). Defining virtual reality: Dimensions determining telepresence. Journal of Communication, 42(4), 73-93. doi:10.1111/j.1460-2466.1992.tb00812.x

Suh, K. S., \& Chang, S. (2006). User interfaces and consumer perceptions of online stores: The role of telepresence. Behaviour \& Information Technology, 25, 99-113. doi:10.1080/01449290500330398

Sundar, S., \& Nass, C. (2000). Source orientation in human-computer interaction: Programmer, networker, or independent social actor? Communication Research, 27(6), 683-703.

Tabachnick, B. G., \& Fidell, L. S. (2007). Using multivariate statistics (5th ed.). Allyn \& Bacon/Pearson Education.

Talmi, D., Anderson, A. K., Riggs, L., Caplan, J. B., \& Moscovitch, M. (2008). Immediate memory consequences of the effect of emotion on attention to pictures. Learning \& Memory (Cold Spring Harbor, N.Y.), 15, $172-182$. doi:10.1101/lm.722908

Tamborini, R., \& Bowman, N. D. (2010). Presence in video games. In C. C. Bracken \& P. Skalski (Eds.), Immersed in media: Telepresence in everyday life, 87-109.

Tian, K., Sautter, P., Fisher, D., Fischbach, S., Luna-Nevarez, C., Boberg, K., Kroger, J., \& Vann, R. (2014). Transforming Health Care: Empowering Therapeutic Communities Through Technology-Enhanced Narratives. The Journal of Consumer Research, 41(2), 237-260. doi:10.1086/676311

van Berlo, Z. M., van Reijmersdal, E. A., Smit, E. G., \& van der Laan, L. N. (2021). Brands in virtual reality games: Affective processes within computer-mediated consumer experiences. Journal of Business Research, 122, 458-465. doi: 10.1016/j.jbusres.2020.09.006

Van Damme, K., All, A., De Marez, L., \& Van Leuven, S. (2019). 360 video journalism: Experimental study on the effect of immersion on news experience and distant suffering. Journalism Studies, 20(14), 2053-2076. doi:10.1080/1461670X.2018.1561208

Van Kerrebroeck, H., Brengman, M., \& Willems, K. (2017a). Escaping the crowd: An experimental study on the impact of a virtual reality experience in a shopping mall. Computers in Human Behavior, 77, 437-450. doi:10.1016/j.chb.2017.07.019 
Van Kerrebroeck, H., Brengman, M., \& Willems, K. (2017b). When brands come to life: Experimental research on the vividness effect of virtual reality in transformational marketing communications. Virtual Reality (Waltham Cross), 21(4), 177-191. doi:10.1007/s10055-017-0306-3

Waterworth, E. L., \& Waterworth, J. A. (2001). Focus, locus, and sensus: The three dimensions of virtual experience. Cyberpsychology \& Behavior, 4(2), 203-213. doi:10.1089/109493101300117893

Wedel, M., Bigné, E., \& Zhang, J. (2020). Virtual and augmented reality: Advancing research in consumer marketing. International Journal of Research in Marketing, 37(3), 443-465.

Wodehouse, A., \& Abba, M. (2016). 3D Visualisation For Online Retail: Factors in Consumer Behavior. International Journal of Market Research, 58(3), 451-472. doi:10.2501/IJMR-2016-027

Xu, Y., Jiang, W., Li, Y., \& Guo, J. (2021). The influences of live streaming affordance in cross-border E-commerce platforms: An information transparency perspective. [JGIM]. Journal of Global Information Management, 30(2), 1-24. doi:10.4018/JGIM.20220301.oa3

Yim, M. Y. C., Cicchirillo, V., \& Drumwright, M. (2012). The impact of stereoscopic 3-D advertising: The role of presence in enhancing advertising effectiveness. Journal of Advertising, 41(2), 113-128. doi:10.2307/41739776

Zillmann, D. (1971). Excitation transfer in communication-mediated aggressive behavior. Journal of Experimental Social Psychology, 7, 419-434. doi:10.1016/0022-1031(71)90075-8

Zillmann, D. (1980). In P. H. Tannenbaum (Ed.), Anatomy of suspense, In the Entertainment Functions of Television (pp. 133-163). Lawrence Erlbaum Associates.

Zillmann, D. (1983). Transfer of excitation in emotional behavior, In J. T. Cacioppo \& R. E. Petty (Eds.). Social Psychophysiology: A Sourcebook, 215-240.

Zillmann, D. (1996). The psychology of suspense in dramatic exposition, In R. D. Kavanaugh, B. Zimmerberg, \& S. Bein (Eds.). Emotion: Interdisciplinary perspectives, 243-272.

Hui-Fei Lin (PhD, Pennsylvania State University) is an Associate professor in the Graduate Institute of Mass Communication, National Taiwan Normal University, Taiwan, R. O. C. Her research focuses on advertising and strategic communications. She has presented numerous research papers on topics such as message framing, new media advertising and communication technology, and has published research papers in several journals including International Journal of Communication, International Journal of Advertising, Expert Systems with Applications, Journal of Internet Technology, Journal of E-Business, Journal of Design, Symmetry, Sustainability, among others. 